\title{
Antiproliferative action of metformin in human lung cancer cell lines
}

\author{
HIRONORI ASHINUMA ${ }^{1}$, YUICHI TAKIGUCHI ${ }^{2}$, SATORU KITAZONO ${ }^{1}$, \\ MIYAKO KITAZONO-SAITOH ${ }^{1}$, ATSUSHI KITAMURA ${ }^{1}$, TETSUHIRO CHIBA $^{3}$, YUJI TADA ${ }^{1}$, \\ KATSUSHI KUROSU ${ }^{1}$, EMIKO SAKAIDA ${ }^{2}$, IKUO SEKINE ${ }^{2}$, NOBUHIRO TANABE ${ }^{1}$, \\ ATSUSHI IWAMA ${ }^{4}$, OSAMU YOKOSUKA ${ }^{3}$ and KOICHIRO TATSUMI ${ }^{1}$ \\ Departments of ${ }^{1}$ Respirology, ${ }^{2}$ Medical Oncology, ${ }^{3}$ Medicine and Clinical Oncology, ${ }^{4}$ Cellular and \\ Molecular Medicine, Graduate School of Medicine, Chiba University, Chiba, Japan
}

Received January 5, 2012; Accepted March 21, 2012

DOI: $10.3892 /$ or.2012.1763

\begin{abstract}
The oral antidiabetic agent metformin has anticancer properties, probably via adenosine monophosphate-activated protein kinase activation. In the present study, growth inhibition was assessed by a clonogenic and by a cell survival assay, apoptosis induction was assessed by Hoechst staining and caspase activities and cell cycle alteration after exposure to metformin, and the interaction of metformin with cisplatin in vitro were elucidated in four human lung cancer cell lines representing squamous, adeno-, large cell and small cell carcinoma. Clonogenicity and cell proliferation were inhibited by metformin in all the cell lines examined. This inhibitory effect was not specific to cancer cells because it was also observed in a non-transformed human mesothelial cell line and in mouse fibroblast cell lines. Inhibition of clonogenicity was observed only when the cells were exposed to metformin for a long period, (10 days) and the surviving fraction, obtained after inhibiting proliferation by increasing the dose, reached a plateau at approximately $0.1-0.3$, indicating the cytostatic characteristics of metformin. Metformin induced significant apoptosis only in the small cell carcinoma cell line. A tendency of cell cycle accumulation at the G0/G1 phase was observed in all four cell lines. Cisplatin, in a dose-dependent manner, severely antagonized the growth inhibitory effect of metformin, and even reversed the effect in three cell lines but not in the adenocarcinoma cell line. The present data obtained using various histological types of human lung cancer cell lines in vitro illustrate the cytostatic nature of metformin and its cytoprotective properties against cisplatin.
\end{abstract}

Correspondence to: Professor Yuichi Takiguchi, Department of Medical Oncology, Graduate School of Medicine, Chiba University, 1-8-1 Inohana, Chuo-ku, Chiba 260-8670, Japan

E-mail: takiguchi@faculty.chiba-u.jp

Key words: metformin, lung cancer, cisplatin, apoptosis, cell line, cell cycle

\section{Introduction}

Metformin is an oral biguanide agent used worldwide to treat non-insulin-dependent diabetes mellitus. The initial reports related to the anticancer effects of metformin were epidemiological studies demonstrating a lower incidence of the occurrence and death of cancer in patients with diabetes mellitus treated with metformin compared to those treated with other antidiabetic agents $(1,2)$. Consequently, these reports have triggered several clinical observational studies. Jiralerspong et al reported a significantly increased pathologically complete response rate in induction chemotherapy for breast cancer in diabetes patients receiving metformin compared to those not receiving metformin (3). Mazzone et al reported that diabetes patients with lung cancer who were previously treated with metformin or thiazolidinediones had a lower incidence of metastatic disease at the time of diagnosis and a reduced risk of death compared to those who did not receive the same treatment (4). Thereafter, the antiproliferative action of metformin was confirmed via in vivo and in vitro experiments in various cancer cell lines including breast (5-8), prostate (9), pancreas (10), and ovarian cancer (11-13) as well as lung adenocarcinoma (8).

Metformin is considered to exert anticancer effects via inhibition of insulin and the mammalian target of rapamycin (mTOR) pathways. Since insulin is a growth-promoting hormone with a mitogenic effect (14), metformin could indirectly inhibit tumor growth by ameliorating hyperinsulinemia, which is frequently observed in patients with non-insulindependent diabetes mellitus (15). In fact, Algire et al reported that metformin inhibited mouse lung tumor growth under specific conditions in which the animals were bred on a highcalorie diet (16). Although this would explain the effect of the agent in vivo, its in vitro effects (5-12) cannot be explained by this anti-insulin action. It has been reported that metformin inhibits complex-I of the respiratory chain in mitochondria, leading to increased AMP expression and liver kinase B1 (LKB1)-mediated activation of AMP kinase, finally inhibiting the mTOR downstream (15). Despite these findings, the precise mechanisms of the metformin-induced effects are not fully understood. In particular, controversy remains about 
whether metformin is apoptotic $(6,10)$ or just cytostatic $(5,9)$ and whether it kills cancer cells synergistically with cytotoxic agents including cisplatin $(11,13)$, paclitaxel $(8)$, and doxorubicin (17), or if it is antagonistic to cisplatin $(18,19)$.

In the present study, the cytotoxic effects of metformin were elucidated in various types of human lung cancer cell lines including squamous, adeno-, large, and small cell carcinoma, together with non-transformed cell lines. The drug-drug interaction between metformin and cisplatin was also investigated.

\section{Materials and methods}

Reagents. Metformin (1,1-dimethylbiguanide hydrochloride, \#D150959-5G; Sigma-Aldrich Co., St. Louis, MO, USA) was diluted in distilled water. Cisplatin solution at a concentration of $0.5 \mathrm{mg} / \mathrm{ml}$ ( $\mathrm{pH} 2.5-5.5)$ was purchased from Nippon Kayaku Co. (Tokyo, Japan).

Cells and cell culture. The human lung cancer cell lines RERFLC-AI (\#RCB0444) and A549 (\#RCB0098) were purchased from the Riken Cell Bank (Tsukuba, Japan), while IA-5 (\#RCB0548) and WA-hT (\#RCB2279) (20) were established and maintained in our laboratory. The established mouse fibroblast cell line Balb/3T3 clone A31 (A31, \#RCB0005) was purchased from the Riken Cell Bank. A nontumorigenic human mesothelial cell line derived from pleural effusion and immortalized by the pRSV-T plasmid Met5A (\#CRL-9444) was purchased from the American Type Culture Collection (Manassas, VA, USA). The histological cell line types included RERF-LC-AI, squamous cell carcinoma; A549, adenocarcinoma; IA-5, large cell carcinoma; and WA-hT, small cell carcinoma. They were cultured as a monolayer in RPMI-1640 medium supplemented with $10 \%$ fetal bovine serum, $100 \mathrm{U} / \mathrm{ml}$ penicillin, and $100 \mathrm{mg} / \mathrm{ml}$ streptomycin in a $37^{\circ} \mathrm{C}$ humidified atmosphere containing $5 \% \mathrm{CO}_{2}$.

Clonogenic assay. For a clonogenic assay involving a 10-day exposure to metformin, subconfluent cultured cells were trypsinized to obtain cell suspensions. Subsequently, a varied number of cells, such that the resulting colony number per plate would be approximately 20-50, were immediately replated onto 6-cm culture dishes in triplicate, cultured for $24 \mathrm{~h}$ in the complete medium until administration of various concentrations of metformin, and further cultured for 10 days without changing the medium. In the clonogenic assay involving 1- and 24-h exposure to the agents, subconfluent cultured cells were treated with various concentrations of agents for 1 or $24 \mathrm{~h}$ and then trypsinized, washed twice with the agent-free complete medium, replated on culture dishes as in the 10-day exposure method, and further cultured for 10 days. In each case, the obtained colonies were counted under a dissecting microscope after a $1 \%$ crystal violet staining.

Cell survival assay. In the cell survival assay, cells were plated onto $6-\mathrm{cm}$ culture dishes in triplicate at a cell concentration of $1 \times 10^{5} /$ plate in complete medium. The cells were cultured for $24 \mathrm{~h}$, and metformin or cisplatin at various concentrations were added to the medium and cultured for an additional 4 days. Viable cells negatively stained with $0.4 \%$ trypan blue were then counted. In the cell survival assays using combined treatment with metformin and cisplatin, doses of cisplatin that reduced the surviving cells to $50 \%$ $\left(\mathrm{IC}_{50}\right)$ and $10 \%\left(\mathrm{IC}_{90}\right)$ with single-agent administration in each cell line were admixed with various concentrations of metformin, with other methods being similar to the methods of the single-agent experiments.

Apoptosis assay. Apoptosis was evaluated using morphological and enzymatic assays, that is, with Hoechst staining and by assessing caspase 3,8 and 9 activities. For Hoechst staining, trypsinized cells together with floating cells were harvested, fixed with $1 \%$ glutaraldehyde, and stained with $1 \mathrm{mM}$ bisbenzimide H 33248 fluorochrome trihydrochloride (Hoechst 33248; Ana Spec, Inc., Fremont, CA, USA). The cells were examined under fluorescence microscopy. Aggregating cells and cells with fragmented chromatin were considered apoptotic. More than 500 cells were evaluated, and the apoptotic cell ratio was recorded in each experiment. The activities of caspases 3, 8 and 9 were evaluated with the synthetic substrates DEVD-, IETD-, and LEHD-pNA, respectively, with the colorimetric assay kits APOPCYTO (Medical \& Biological Laboratories Co., Nagoya, Japan) by monitoring the absorbance at a wavelength of $405 \mathrm{~nm}$ to measure p-nitroanilide (pNA) cleaved from synthetic substrates with cell extracts.

Cell cycle analysis. Cell cycle distribution was determined by the propidium iodide single-color method using a flow cytometer (FACSCanto II; BD Biosciences, San Jose, CA, USA) according to the manufacturer's instructions. In brief, cells were trypsinized, fixed with 70\% ethanol, washed with PBS(-), and treated with PI/RNase Staining buffer (BD Biosciences) at a concentration of $2 \times 10^{6}$ cells $/ \mathrm{ml}$. The data were analyzed using the BD FACSDiva software (BD Biosciences).

\section{Results}

Colony formation and cell proliferation. Metformin exerted inhibitory effects on the clonogenicity of the 4 human lung cancer cell lines as well as that of non-transformed human mesothelial cell line and a mouse fibroblast cell line in a dosedependent fashion when they were exposed to metformin for 10 days. On the other hand, a 1-h exposure to metformin did not show any significant inhibitory effect on the clonogenicity of any cell line, whereas a 24-h exposure showed slight suppression of clonogenicity in the A549, IA-5, and Met5A lines (Fig. 1). According to the cell survival assay, inhibition of cell proliferation was observed in the 4 human lung cancer cell lines when they were exposed to metformin for 4 days (Fig. 2). Cell proliferation inhibitory effects on the 4 cell lines exposed to cisplatin for 4 days are shown in Fig. 3.

Apoptosis. Apoptosis was assessed by Hoechst staining and by determining the activities of caspases 3,8 and 9. The effects of metformin at $\mathrm{IC}_{30}$ and $\mathrm{IC}_{70}$ were examined in each cell line. Experiments with cisplatin at $\mathrm{IC}_{70}$ were conducted for comparison with metformin, and those with cisplatin at a higher dose were conducted for assay control. Apoptosis assessed by Hoechst staining failed to show significant apoptosis in all lung cancer cell lines except WA-hT, which had a significantly higher ratio of apoptosis compared to the non-treated cells 


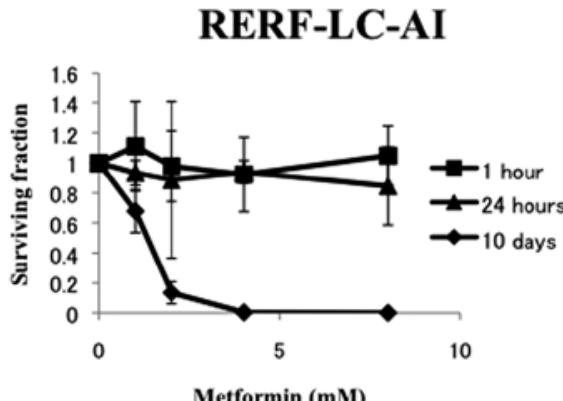

Metformin (mM)

WA-hT

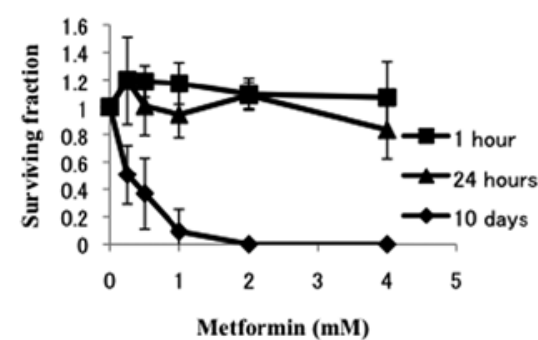

A549

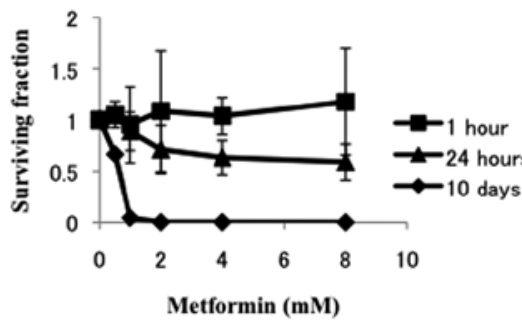

Met5A

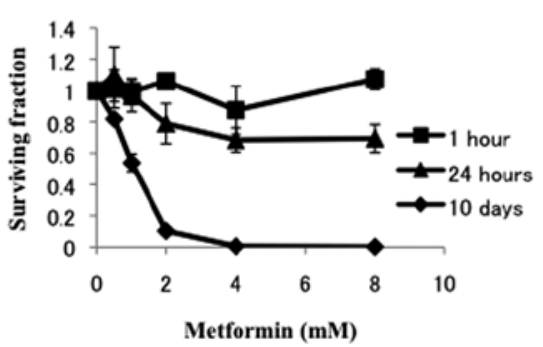

IA-5

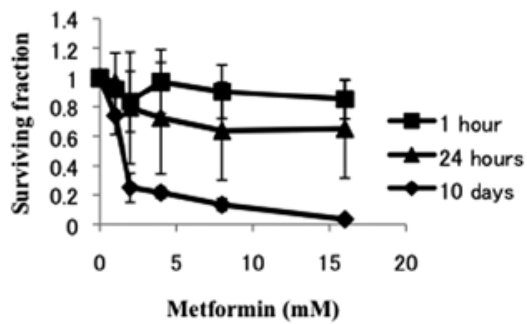

A31

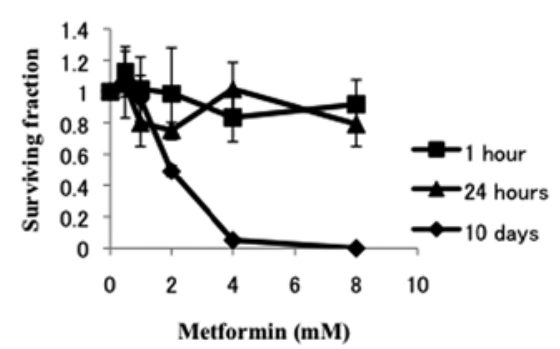

Figure 1. Survival curves drawn based on the results of the clonogenic assay. The cells were exposed to various concentrations of metformin for 1 or $24 \mathrm{~h}$ before being trypsinized and plated for colony formation in complete medium. Otherwise, the cells were trypsinized and plated for colony formation by further culture for 10 days in metformin-containing complete medium. RERF-LC-AI, A549, IA-5, and WA-hT represent squamous, adeno-, large cell, and small cell lung carcinoma cell lines, respectively. Met5A and A31 represent non-transformed human mesothelial and mouse fibroblast cell lines, respectively. Each experiment was conducted in triplicate and repeated 3 times. The mean value of each triplicate represents the value of each experiment, while the mean \pm SD of the 3 experimental results were calculated. The dot and bar represent mean and SD at each point.

RERF-LC-AI

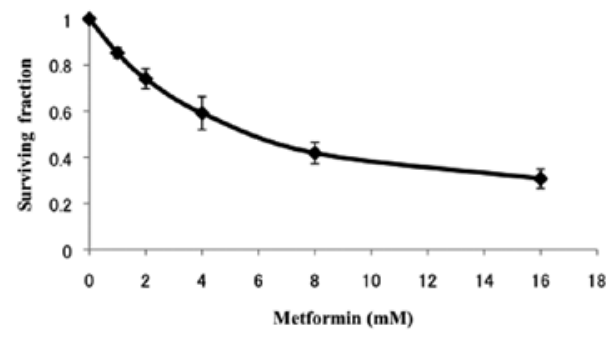

IA-5

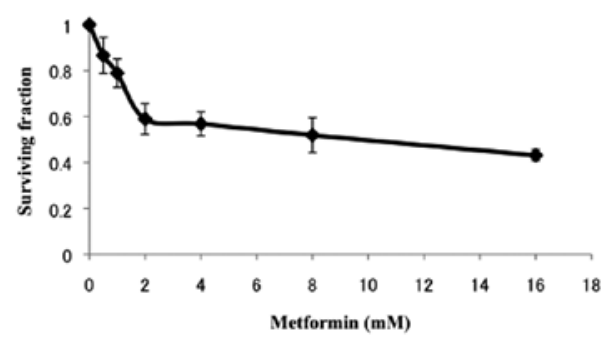

A549

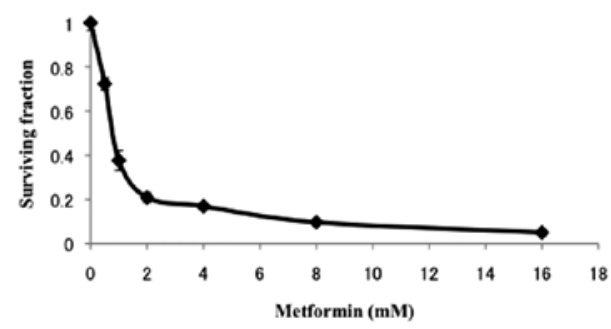

WA-hT

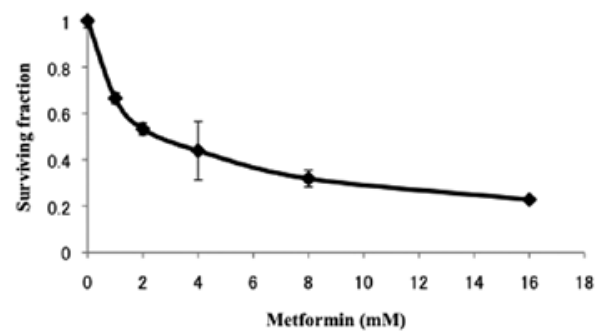

Figure 2. Survival curves drawn based on the results of the cell survival assay. The cells were plated at a concentration of $10^{5}$ cells/plate with complete medium containing metformin at various concentrations, and were further cultured for 4 days with metformin until the surviving cells were counted. Each experiment was conducted in triplicate and repeated 3 times. The mean value of each triplicate represents the value of each experiment, and the mean \pm SD of the 3 experimental results were calculated. The dot and bar represent mean and SD at each point.

(Fig. 4A). Apoptosis assessed by determining the activities of caspases 3, 8 and 9 revealed results similar to that of Hoechst staining (Fig. 4B).
Cell cycle distribution. In cell cycle analysis, the effects of metformin at $\mathrm{IC}_{30}$ and $\mathrm{IC}_{70}$ were compared to those of cisplatin at $\mathrm{IC}_{70}$ and at a higher concentration in each cell line. Although 
RERF-LC-AI

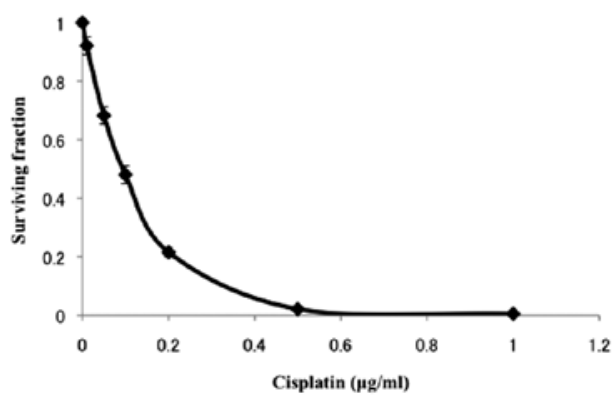

IA-5

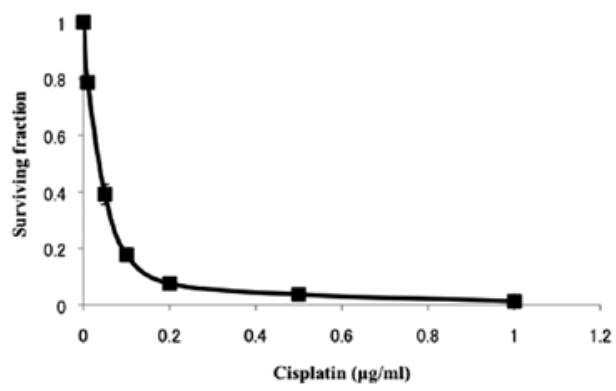

A549

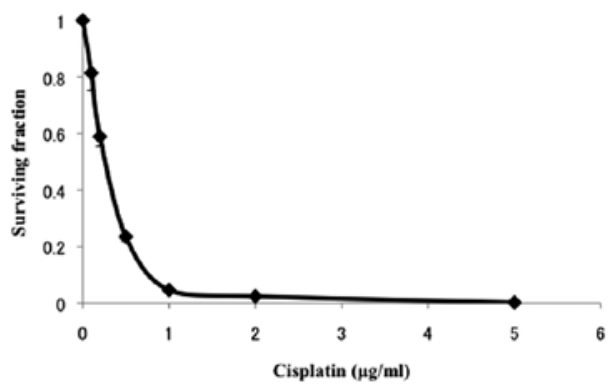

WA-hT

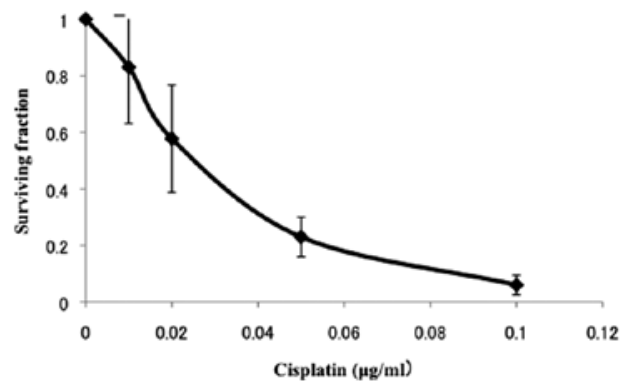

Figure 3. Survival curves drawn based on the results of the cell survival assay. The cells were treated with various concentrations of cisplatin instead of metformin. Other procedures were conducted as mentioned in Fig 2

there was no statistically significant difference except for the case of RERF-LC-AI, metformin induced G0/G1 phase accumulation in all 4 cell lines, whereas cisplatin at $\mathrm{IC}_{70}$ caused significant G2/M phase accumulation in RERF-LC-AI and WA-hT, and G0/G1 phase accumulation in A549 cells. On the other hand, higher concentrations of cisplatin caused significant G2/M phase accumulation in all 4 cell lines (Fig. 5).

Interaction of metformin and cisplatin. In this experiment, cisplatin at $\mathrm{IC}_{50}$ and $\mathrm{IC}_{90}$ in each cell line was combined with metformin. The inhibitory effects of metformin on cell proliferation were slightly suppressed with cisplatin at $\mathrm{IC}_{50}$ in all cells, except A549 cells. A higher dose $\left(\mathrm{IC}_{90}\right)$ of cisplatin almost completely countervailed or even reversed the effects of metformin in all cell lines except for A549, where a modest, but significant, sub-additive effect was observed (Fig. 6).

\section{Discussion}

Metformin inhibited clonogenicity and cell proliferation in all 4 cell lines in a similar manner. On the other hand, WA-hT cells showed significantly higher sensitivity to cisplatin compared to the other cell lines. Concerning clonogenicity, the inhibitory effect of metformin was not specific to cancer cells because non-transformed mouse fibroblast and human mesothelial cell lines were also inhibited. Contrary to molecular targeted agents which specifically kill cancer cells harboring their specific targets, classical cytotoxic agents kill cells similarly even between cancer and non-transformed cells in vitro but preferably kill the former over the latter in vivo with differential effects to the cells according to different dividing capabilities. Therefore, it is speculated that metformin does not attack cancer-specific target molecules. In addition, the clonogenic assay disclosed that it is necessary to expose the cells to metformin for long periods of time to exert the inhibitory effects. As the surviving fraction reached a plateau in the range of $0.1-0.3$ in the various cell lines with increasing doses of metformin (Fig. 2), the concentrations of $\mathrm{IC}_{30}$ and $\mathrm{IC}_{70}$ were chosen for further elucidating the mechanism of action.

Metformin did not enhance apoptosis at relatively low concentrations, as assessed by Hoechst staining and caspase activities in all cell lines except for WA-hT. Although the differences were not statistically significant except in RERFLC-AI, metformin at $\mathrm{IC}_{30}$ and $\mathrm{IC}_{70}$ in each cell line tended to cause G0/G1 phase accumulation. Specifically, metformin exerted cytotoxicity by G0/G1 arrest in RERF-LC-AI, A549, and IA- 5 and by both G0/G1 arrest and apoptosis in WA-hT cells. Although metformin may induce a different effect at higher concentrations, such high concentrations would not be clinically relevant. More specifically, the mean peak plasma concentration $\left(\mathrm{C}_{\max }\right)$ in 5 Japanese diabetes patients was reportedly $0.85 \pm 0.19 \mu \mathrm{g} / \mathrm{ml}\left(5.1 \pm 1.1 \times 10^{-3} \mathrm{mM}\right)$ when $250 \mathrm{mg}$ of metformin was orally administered (21). Since the maximal single dose of $750 \mathrm{mg}$ metformin is prescribed 3 times a day, an estimation of the $\mathrm{C}_{\max }$ would be $15 \times 10^{-3} \mathrm{mM}$. Although the dose range employed in the present research is approximately 100-fold higher than the plasma concentration that is achieved by conventional clinical application, the present results still seem clinically relevant for several reasons; a) chronic administration of metformin for months or even years in the clinical setting would be possible and the long-term exposure may augment its effects as demonstrated in Fig. 1; b) metformin accumulates in tissues at much higher concentrations than in the blood (22); and c) a dose-finding study for cancer treatment might determine the maximal tolerated dose of metformin at a much higher level than currently used for diabetic patients. Moreover, further elucidating the antiproliferative action of 
A

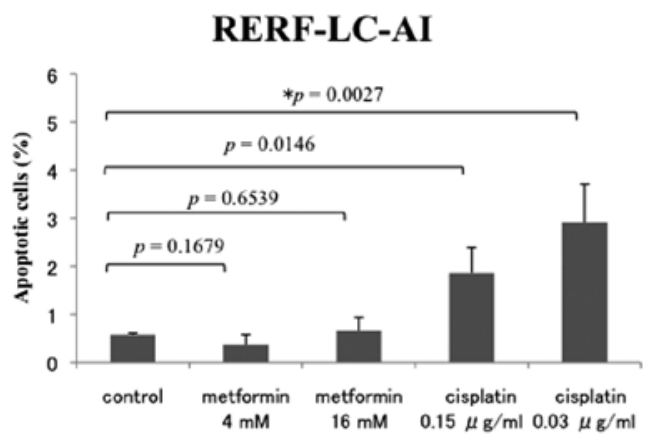

IA-5

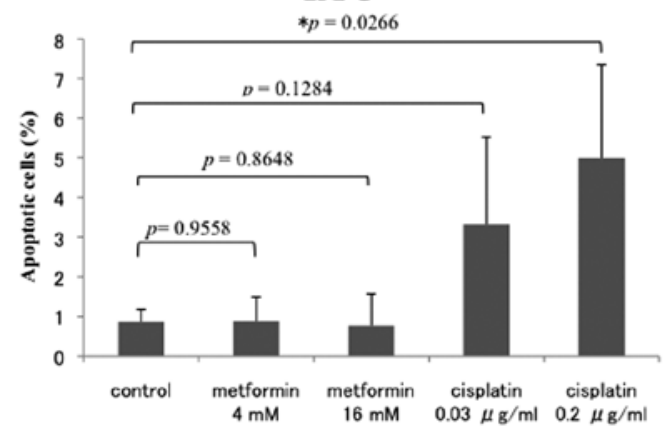

B
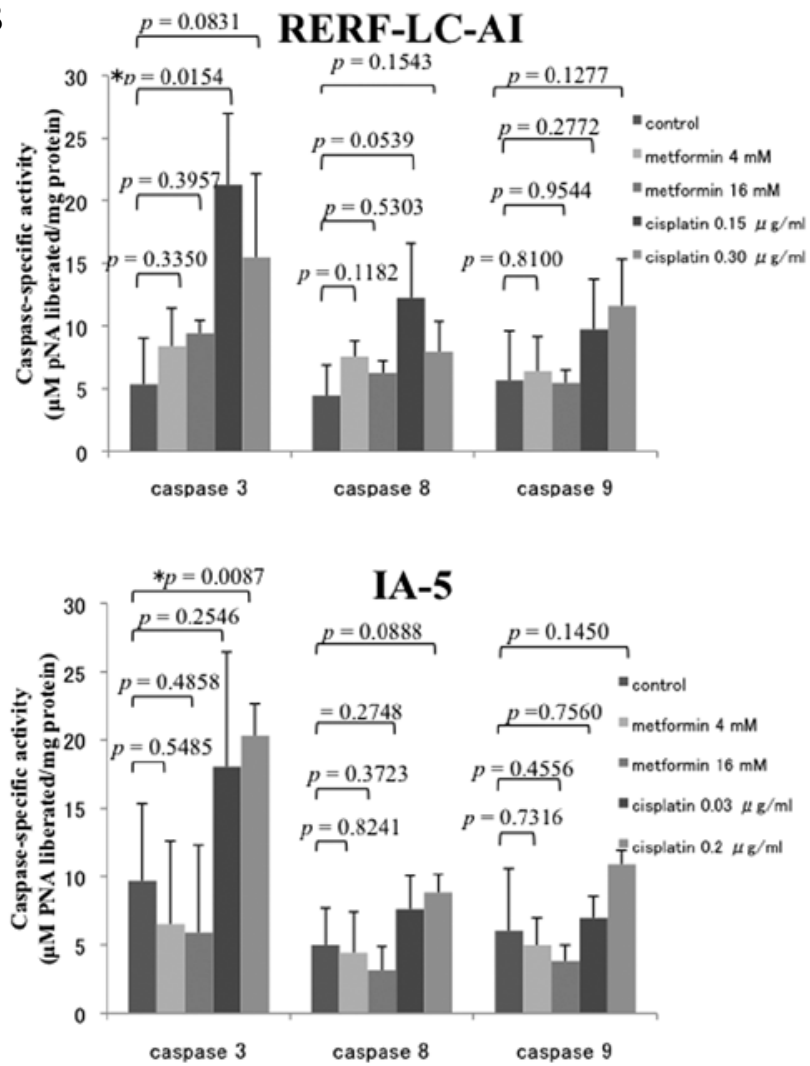
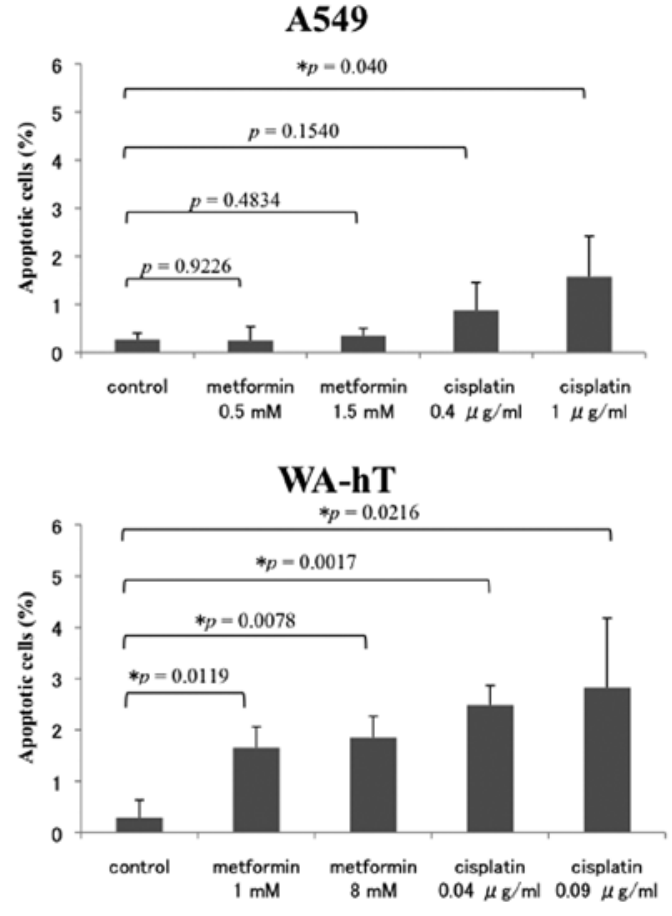
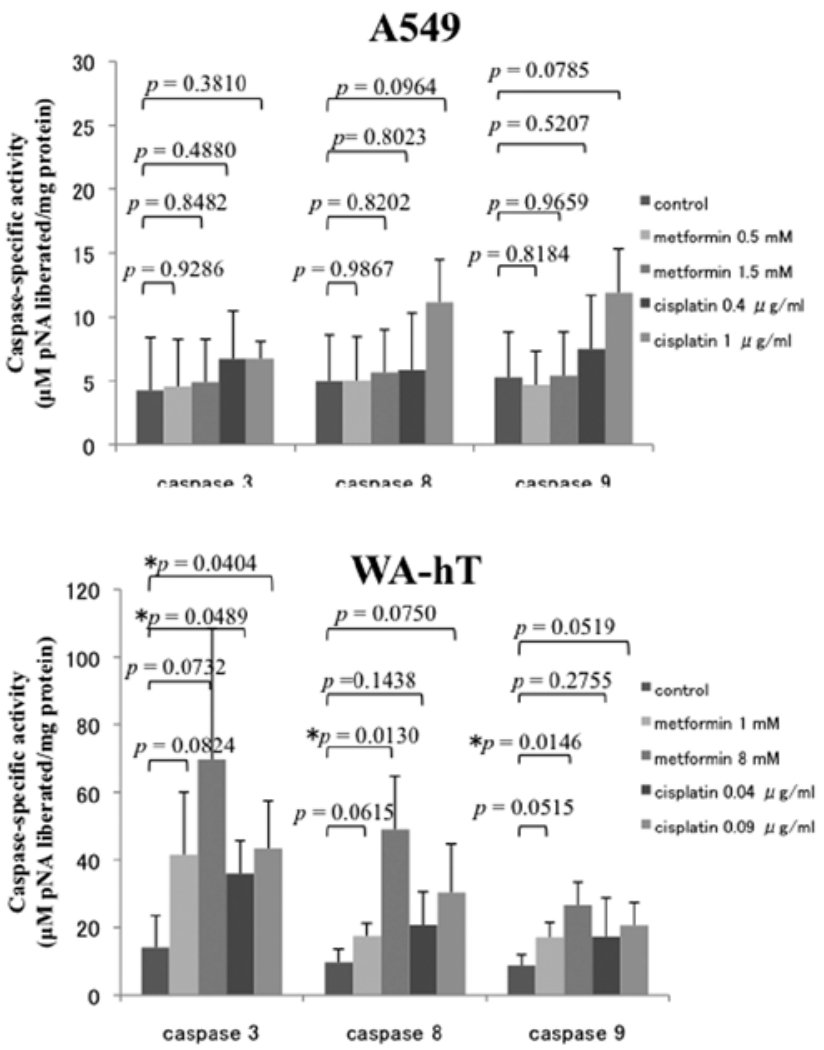

Figure 4. Apoptotic induction by treatment with metformin or cisplatin assessed by (A) Hoechst staining and (B) by caspase activities. The concentrations of metformin were $\mathrm{IC}_{30}$ and $\mathrm{IC}_{70}$ for each cell line. The concentrations of cisplatin were $\mathrm{IC}_{70}$ and higher for each cell line. Differences from the control (no exposure to agents) were compared using the Student's t-test, and the resulting p-values are presented. "p<0.05 (two-tailed). Each experiment was repeated 3 times, and the mean \pm SD values of the 3 experimental results are presented.

metformin may lead to the discovery of crucial target molecules for more effective new agents.

There is an increasing number of reports on the antineoplastic effects of metformin highlighting controversy in relation to its apoptotic induction and cell cycle alteration. Contrary to some studies reporting enhanced apoptosis in triple-negative breast cancer (6) and pancreatic cancer cells (10), others failed to observe apoptosis in non-triple-negative 

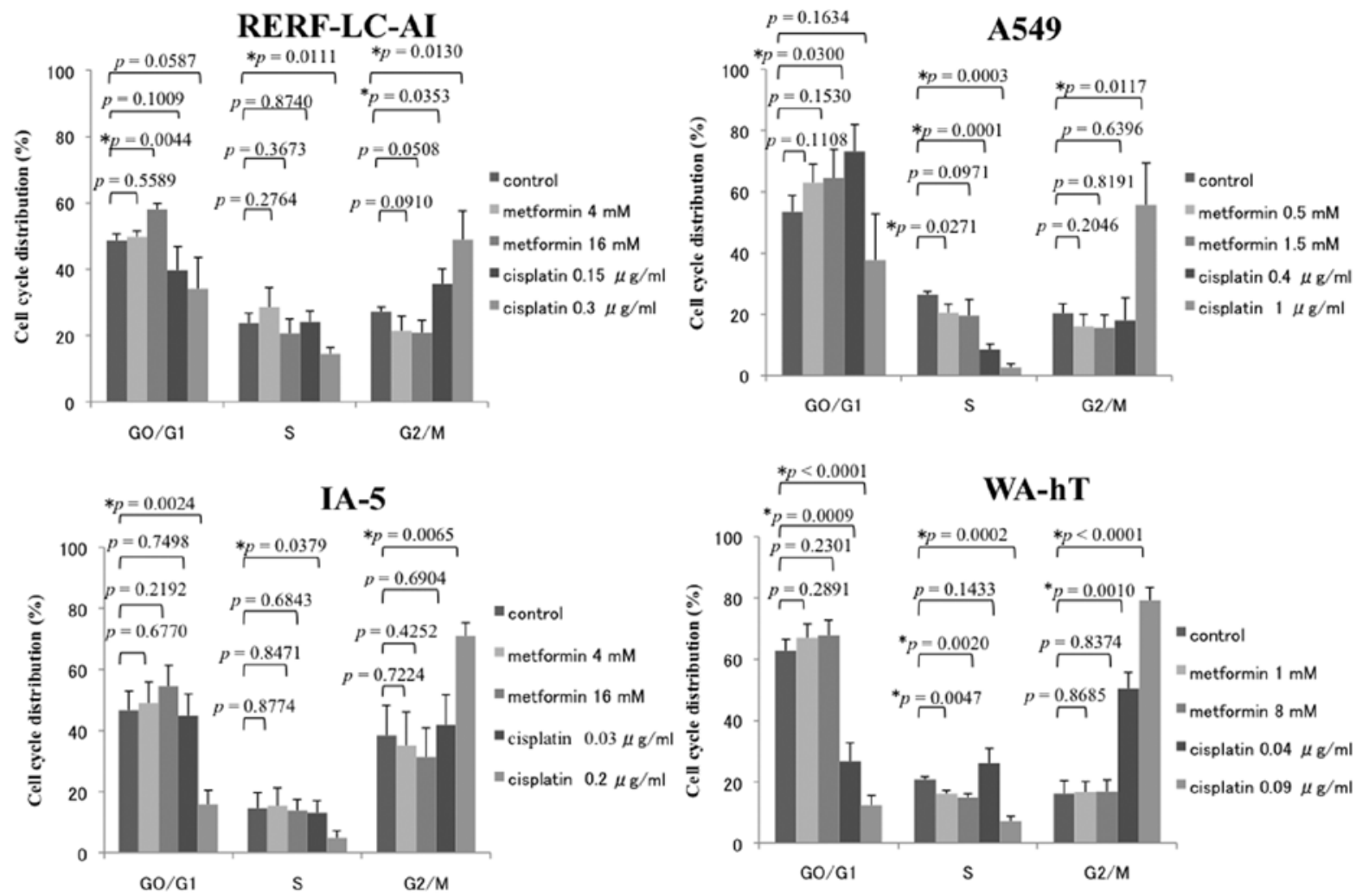

Figure 5. Alteration of cell cycle distribution by metformin or cisplatin assessed using the propidium iodide single-color method with a flow cytometer Similarly to apoptosis analysis, the concentrations of metformin were $\mathrm{IC}_{30}$ and $\mathrm{IC}_{70}$ for each cell line, while the concentrations of cisplatin were $\mathrm{IC}_{70}$ and higher for each cell line. Differences from the control (no exposure to agents) were compared using Student's t-test and the resulting $\mathrm{p}$-values are presented. ${ }^{*} \mathrm{p}<0.05$ (two-tailed). Each experiment was repeated 3 times, and the mean \pm SD values of the 3 experimental results are presented.

LCA

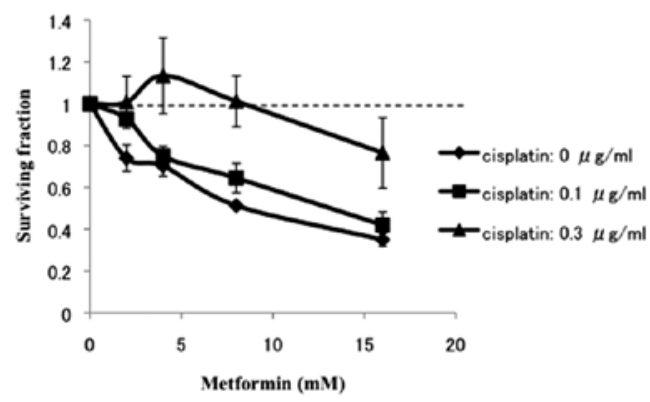

IA-5

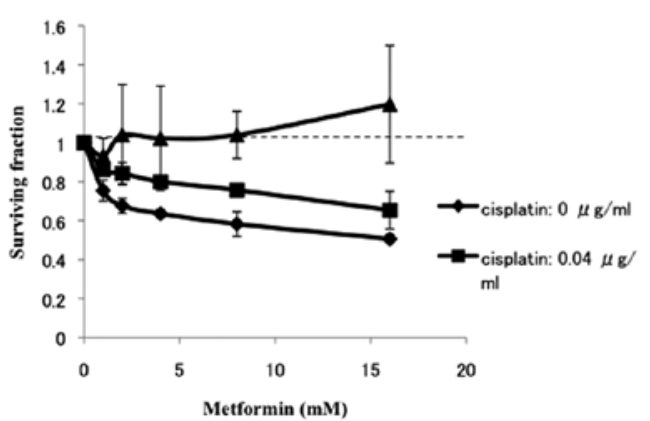

A549

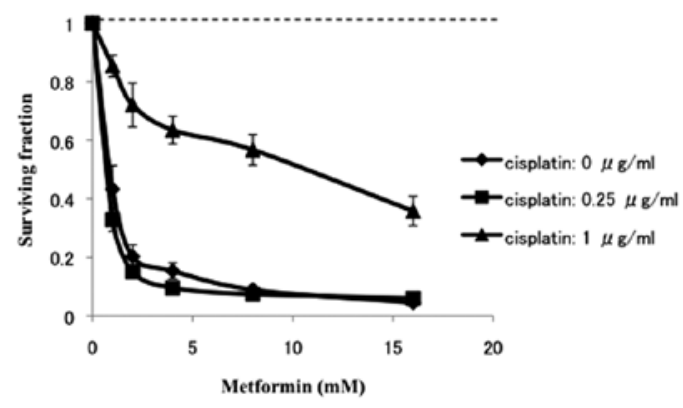

WA-hT

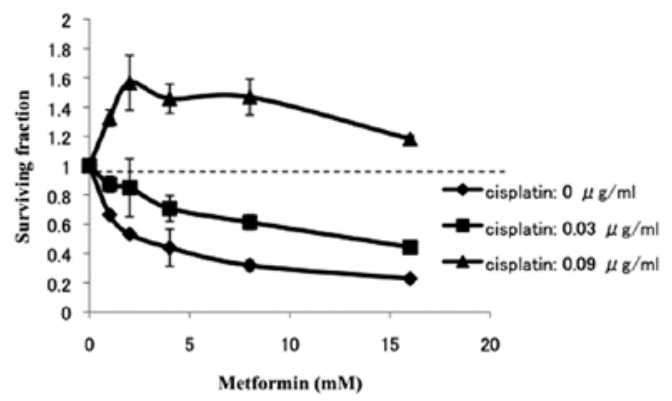

Figure 6. Interaction between metformin and cisplatin on cell proliferation inhibition. The cell survival assay was conducted using various concentrations of metformin as described in Fig. 2 except that the cells were exposed to 3 different concentrations of cisplatin, its $\mathrm{IC}_{50}$ and $\mathrm{IC}_{90}$ for each cell line and 0 , together with metformin. In each curve with a defined cisplatin concentration, a fraction against the value without metformin was plotted at each metformin concentration point. Therefore, the curves located above the curve without cisplatin represent the antagonistic effects between the 2 agents. In particular, curves exceeding the line at fraction 1 (dotted lines) represent inverse effects, i.e., cell proliferation-enhancing effects by metformin treatment. Each experiment was conducted in triplicate and repeated 3 times. The mean value of each triplicate represents the value in each experiment, and the mean \pm SD of the 3 experimental results were calculated. The dot and bar represent mean and SD at each point. 
breast cancer (5) and a prostatic cancer cell line (9). Notably, cell cycle accumulation at the $\mathrm{S}$ phase was observed in a study on triple-negative breast cancer (6) and a pancreatic cancer cell line (10) that accompanied apoptosis enhancement, whereas an arrest at the G1 check point was observed in the non-triple-negative breast cancer (5) and the prostatic cancer cell line (9), and this arrest was not accompanied by apoptosis enhancement. In addition, G1 arrest was observed in an ovarian cancer cell line (12). The present results also differed among the cell lines, each of them representing a different histological type of human lung cancer. Metformin did not exert apoptosis induction but showed a tendency toward G0/G1 arrest in RERF-LC-AI, A549, and IA-5 cell lines, similarly to the results with non-triple-negative breast cancer (5) and prostatic cancer cell lines (9). However, WA-hT simultaneously underwent apoptosis and slight G0/G1 arrest. In view of the diversified results even among the 4 cell lines of a single disease, it would not be inappropriate to conclude that metformin affects different cancers or cancer cell lines differently.

The results of the combined effects of metformin and cisplatin are noteworthy. Administration of cisplatin at $\mathrm{IC}_{50}$ along with metformin decreased the sensitivity to metformin in all 4 cell lines. Moreover, the combined use of metformin and high-dose cisplatin enhanced metformin-induced growth in all cell lines, excluding A549, because the cell survival curves of the other 3 cell lines exceeded the lines of fraction 1. Controversy exists in the literature with respect to the interaction with cisplatin. According to the research conducted by Gotlieb et al (11) and Rattan et al (13), metformin with cisplatin synergistically killed ovarian cancer cells. In contrast, Janjetovic et al (18) reported an antagonistic interaction between metformin and cisplatin in human glioma, rat glioma, human neuroblastoma, mouse fibrosarcoma, and human leukemia cell lines, possibly via an AMP kinase-independent upregulation of the Akt survival pathway. However, they also found augmented cisplatin sensitivity by metformin in a mouse melanoma cell line. Harhaji-Trajkovic et al (19) reported the antagonistic action of metformin on cisplatin. These findings again suggest that metformin affects different types of cancer, differently. On the other hand, the interaction between metformin and cisplatin in the present study was unexceptionally antagonistic in all 4 cell lines.

In conclusion, metformin inhibited the proliferation of various histological types of human lung cancer cell lines, possibly by varied mechanisms including apoptosis induction and G0/G1 arrest according to the cell line. Metformin and cisplatin were antagonistic in all 4 investigated cell lines. Taking account of its limited clinical adverse effects, metformin may have the potential for use in cancer therapy with adequate consideration of drug-drug interaction.

\section{Acknowledgements}

This study was financially supported by a Grant-in-Aid for Scientific Research (grant no. 23591136) from the Japan Society for the Promotion of Science and the Ministry of Education, Culture, Sports, Science and Technology of Japan.

\section{References}

1. Evans JM, Donnelly LA, Emslie-Smith AM, Alessi DR and Morris AD: Metformin and reduced risk of cancer in diabetic patients. BMJ 330: 1304-1305, 2005.

2. Bowker SL, Majumdar SR, Veugelers P and Johnson JA: Increased cancer-related mortality for patients with type 2 diabetes who use sulfonylureas or insulin. Diabetes Care 29: 254-258, 2006.

3. Jiralerspong S, Palla SL, Giordano SH, et al: Metformin and pathologic complete responses to neoadjuvant chemotherapy in diabetic patients with breast cancer. J Clin Oncol 27: 3297-3302, 2009.

4. Mazzone PJ, Rai HS, Beukemann M, Xu M, Abdallah R and Sasidhar M: The effect of metformin and thiazolidinedione use on lung cancer. Chest 138: 882A, 2010.

5. Alimova IN, Liu B, Fan Z, et al: Metformin inhibits breast cancer cell growth, colony formation and induces cell cycle arrest in vitro. Cell Cycle 8: 909-915, 2009.

6. Liu B, Fan Z, Edgerton SM, et al: Metformin induces unique biological and molecular responses in triple negative breast cancer cells. Cell Cycle 8: 2031-2040, 2009.

7. Zakikhani M, Dowling R, Fantus IG, Sonenberg N and Pollak M: Metformin is an AMP kinase-dependent growth inhibitor for breast cancer cells. Cancer Res 66: 10269-10273, 2006.

8. Rocha GZ, Dias MM, Ropelle ER, et al: Metformin amplifies chemotherapy-induced AMPK activation and antitumoral growth. Clin Cancer Res 17: 3993-4005, 2011.

9. Ben Sahra I, Laurent K, Loubat A, et al: The antidiabetic drug metformin exerts an antitumoral effect in vitro and in vivo through a decrease of cyclin D1 level. Oncogene 27: 3576-3586, 2008.

10. Wang LW, Li ZS, Zou DW, Jin ZD, Gao J and Xu GM: Metformin induces apoptosis of pancreatic cancer cells. World J Gastroenterol 14: 7192-7198, 2008.

11. Gotlieb WH, Saumet J, Beauchamp MC, et al: In vitro metformin anti-neoplastic activity in epithelial ovarian cancer. Gynecol Oncol 110: 246-250, 2008.

12. Rattan R, Giri S, Hartmann LC and Shridhar V: Metformin attenuates ovarian cancer cell growth in an AMP-kinase dispensable manner. J Cell Mol Med 15: 166-178, 2011.

13. Rattan R, Graham RP, Maguire JL, Giri S and Shridhar V: Metformin suppresses ovarian cancer growth and metastasis with enhancement of cisplatin cytotoxicity in vivo. Neoplasia 13: 483-491, 2011.

14. Pollak M: Insulin and insulin-like growth factor signalling in neoplasia. Nat Rev Cancer 8: 915-928, 2008.

15. Goodwin PJ, Ligibel JA and Stambolic V: Metformin in breast cancer: time for action. J Clin Oncol 27: 3271-3273, 2009.

16. Algire C, Zakikhani M, Blouin MJ, Shuai JH and Pollak M: Metformin attenuates the stimulatory effect of a high-energy diet on in vivo LLC1 carcinoma growth. Endocr Relat Cancer 15: 833-839, 2008.

17. Iliopoulos D, Hirsch HA and Struhl K: Metformin decreases the dose of chemotherapy for prolonging tumor remission in mouse xenografts involving multiple cancer cell types. Cancer Research 71: 3196-3201, 2011.

18. Janjetovic K, Vucicevic L, Misirkic M, et al: Metformin reduces cisplatin-mediated apoptotic death of cancer cells through AMPK-independent activation of Akt. Eur J Pharmacol 651: 41-50, 2011

19. Harhaji-Trajkovic L, Vilimanovich U, Kravic-Stevovic T, Bumbasirevic V and Trajkovic V: AMPK-mediated autophagy inhibits apoptosis in cisplatin-treated tumour cells. J Cell Mol Med 13: 3644-3654, 2009.

20. Sugimoto T, Takiguchi Y, Kurosu K, et al: Growth factor-mediated interaction between tumor cells and stromal fibroblasts in an experimental model of human small-cell lung cancer. Oncol Rep 14: 823-830, 2005.

21. Iwase M, Nohara S, Sasaki N, et al: Pharmacokinetics study of low dose of metformin clinically used in Japan. J Japan Diab Soc 47: 197-201, 2004.

22. Wilcock $\mathrm{C}$ and Bailey CJ: Accumulation of metformin by tissues of the normal and diabetic mouse. Xenobiotica 24: 49-57, 1994. 